\title{
PÓS-ESTRUTURALISMO E A CRÍTICA COMO REPETIÇÃO
}

\section{Cristiano Mendes}

Universidade de Brasília (UnB), Brasília - DF, Brasil. E-mail: cristianomendes@gmail.com

DOI: http//dx.doi.org/10.17666/308845-59/2015

\section{O artista da fome}

Kafka, em seu conto "Um artista da fome" (2002), retrata a luta pela sobrevivência de um jovem artista de circo medieval. Apresentando-se ao público dentro de uma jaula, o artista da fome possui o dom de ficar dias em jejum, superando, a cada dia, a capacidade humana de se manter vivo sem alimentação. $\mathrm{O}$ público paga para ver o espetáculo e conferir, com seus próprios olhos, o desafio do artista em se manter, a cada temporada, um tempo maior sem a ingestão de alimentos. O problema do artista está na insaciedade do público. Quem assiste a ele sempre espera para a apresentação seguinte um número superior de dias dentro da jaula. Sendo a capacidade de jejuar o único dom do protagonista, este se vê obrigado a ficar cada vez mais sem alimento para ganhar ren-

Aprovado em 03/03/2015 da que lhe permita sobreviver entre uma temporada e outra.

O conto de Kafka é a metáfora das contradições presentes na condição humana. A busca pela sobrevivência requer a morte rotineira. A ânsia em se manter vivo só é inteligível a partir do contraponto construído pelo seu inverso. É morrendo a cada dia que conseguimos manter nossa existência.

\section{Pós-estruturalismo em Relaçóes Internacionais}

$\mathrm{O}$ presente artigo pretende questionar quais seriam as possibilidades críticas passíveis de serem elaboradas a partir de abordagens pós-estruturalistas, mantendo-se a coerência com os pressupostos encontrados nessas perspectivas. A partir da análise de estratégias utilizadas por autores pós-estruturalistas no campo das Relaçóes Internacionais, prin- 
cipalmente vindas da obra de R. Walker, creio que a radicalização crítica prevista pelo pós-estruturalismo estaria não no conceito tradicional de crítica positivista como algo que denuncia contradiçóes ou fragilidades de determinado fenômeno que se quer verdade. Também, a indicação das condiçōes sob as quais se assenta o conhecimento produzido, bem como as limitações geradas por metáforas inerentes a este conhecimento, é restrita à necessidade de adoção de determinadas categorias espaço-temporais que se quer relativizar. A crítica pós-estrutural estaria, portanto, na repetição daquilo que se quer criticar. É pela aceitação incondicional e extrema de um argumento e na reprodução à exaustão da sua verdade que conseguimos esgarçar os sentidos daquilo que queremos anular.

Desde a última década do século XX, os debates teóricos no âmbito das Relaçôes Internacionais caracterizam-se pela crescente presença de abordagens que questionam as teorias positivistas, principalmente o neorrealismo. Dentre as críticas produzidas por essas novas perspectivas, dois grandes grupos podem ser destacados: autores construtivistas, que aceitam elementos das abordagens tradicionais, mas acrescentam variáveis mais subjetivas às análises ${ }^{1}$, e autores que relativizam de maneira radical as perspectivas mainstream a partir de um marco pós-estruturalista. ${ }^{2}$ Estes últimos extrapolam os limites do conceito de estrutura e analisam fenômenos identificando aberturas e instabilidades que produzem um constante fluxo de sentidos em relação ao objeto estudado. Apesar de não haver consenso sobre o significado do termo "pós-estruturalismo", alguns pontos podem ser destacados.

O conceito de pós-estruturalismo é geralmente localizado dentro da corrente mais abrangente chamada pós-modernidade. Nascida como extensão do período moderno, a pós-modernidade seria a radicalização daquele primeiro movimento caracterizado por rupturas com o passado e pela emergência de um novo paradigma nas artes e na vida de modo geral. A proposta modernista tinha como objetivo instrumentalizar a individualidade para, com foco em aspectos institucionais, produzir mais objetividade na interpretação do mundo. O pós-modernismo estenderia essa revolução da modernidade para a vida rotineira, enfatizando o caráter estético e hedonista da existência (Best e Kellner, 1991). Entretanto, enquanto a modernidade enfatiza a racionalidade e o papel da coerência e da unidade na interpretação do mundo, o pós-modernismo seria a celebração dos aspectos contraditórios e da não unidade da realidade. $\mathrm{O}$ conhecimento do mundo somente é possível, na abordagem pós-moderna, como perspectivas fragmentadas que não só explicam, mas também participam como elementos formadores do real. Assim, o pós-modernismo teria uma abordagem que iria além dos limites considerados acadêmicos, podendo ser utilizado de maneira mais ampla para denominar qualquer aspecto da vida, desde as ciências até as artes.

O "pós-estruturalismo", denominação utilizada para referências acadêmicas, é uma das perspectivas teóricas da abordagem pós-moderna. Ele, até certo ponto, adota e amplia elementos do estruturalismo para além de suas concepçôes mais tradicionais. Enquanto o estruturalismo abarca a produção, principalmente das ciências humanas, a partir da segunda metade do século XX - não estando incluído, portanto, no projeto da pós-modernidade -, o pós-estruturalismo teria sua gênese nos trabalhos de Derrida e Foucault, a partir da década de 1960, e seria coerente com tradiçôes não racionalistas, sobretudo com as obras de Nietzsche do século XIX. ${ }^{3}$ O estruturalismo enfatiza a ideia de estruturas estáveis, partindo de pressupostos saussurianos sobre a independência de sistemas. Já os pós-estruturalistas foram além, trabalhando com ideias como instabilidades estruturais (aberturas) e relativizações do processo de significação da realidade.

Para os pós-estruturalistas, ao contrário [dos estruturalistas], o significado é apenas um momento em um processo de significação sem fim onde o sentido é produzido, não em uma estável e referencial relação entre sujeito e objeto, mas apenas dentro de um infinito e intertextual jogo de significações (Best e Kellner, 1991, p. 21, tradução nossa).

Apesar de não haver consenso sobre a designação do termo, existe uma percepção minimamente compartilhada de que um dos pressupostos que embasam qualquer abordagem pós-estrutural é a im- 
possibilidade de definir objetivamente qualquer tipo de conceito. Assim, a resposta para a definição do próprio termo somente será encontrada a partir de perspectivas que o negam, mesmo porque a pergunta "o que significa pós-estruturalismo?" apenas faz sentido para aqueles que são classificados fora dos limites criados por essa designação. A própria tentativa de definição do conceito já implica uma estratégia de construçôes limítrofes que, em última instância, tenta organizar os campos de saber a partir de táticas que situam discursos em determinadas tradiçôes ou abordagens. Essa tentativa de localização discursiva pode ser inserida em um projeto maior de classificaçôes textuais que são a base para o controle e a legitimação de perspectivas na produção e na construção de campos do saber. ${ }^{4}$

Mas onde os construtivistas quiseram - ou talvez até mesmo tenham visto uma vantagem estratégica - adotar um rótulo disciplinar, com o passar dos anos muito poucos trabalhos se autodenominaram pós-modernos ou pós-estruturalistas. Quando isso ocorreu, geralmente foi adotada a última categoria, debatendo pós-estruturalismo (não antiestruturalismo) linguístico, filosofia, teoria social e teoria literária (mais especificamente escritores como Nietzsche, Kristeva, Foucault e Derrida), enquanto o "pós-modernismo" se referia a uma ordem histórica particular (Hansen, 1997; Waever, 2002). Essa ausência de autodeclaração implicou no fato de que esforços para apresentar o pós-estruturalismo como uma abordagem coerente foram sustentados mais por seus críticos (para exceções, ver Der Derian e Shapiro, 1989; Ashley e Walker, 1990; George, 1994) (Hansen, 2006, p. 4, tradução nossa).

Entre os autores pós-estruturalistas de Relaçōes Internacionais, um dos que mais se destaca é Rob Walker - referência constante em trabalhos acadêmicos que utilizam esta abordagem. Buscando localizar as condiçōes de construção das categorias fundacionais do campo de Relaçôes Internacionais, esse autor irá propor uma desconstruçāo da metáfora insideloutside e, consequentemente, realizar uma relativização das fronteiras que separam esse campo de conhecimento daquele da ciência política. Através de um processo de tresvaloração entre o que acontece dentro e fora dos Estados, Walker constrói uma argumentação segundo a qual as perguntas elaboradas sobre $\mathrm{o}$ ambiente internacional já seriam limitadas em sua capacidade de resposta, uma vez aceita essa metáfora.

\section{Insideloutside}

Em seus livros Insideloutside: international relations as political theory (1995) e After the globe, before the world (2010), Walker resgata a lógica derridiana do contraponto gerando a unidade e mostra as contradiçôes existentes nos discursos sobre Relaçôes Internacionais. Segundo o autor, o campo de conhecimento das Relações Internacionais somente é passível de ser considerado nas suas especificidades a partir da metáfora insideloutside. Como toda metáfora é arbitrária, a dicotomia fundadora do conceito de internacional também tem como base pressupostos não discutidos. Nesse caso, supõe-se que o ambiente interno aos Estados seja diferente, em termos qualitativos, ao internacional.

Para Walker (1995), a crença disseminada, principalmente pelas abordagens tradicionais, de que no ambiente internacional vive-se uma situação de anarquia e, consequentemente, de desconfiança, conflitos e ausência de homogeneidade cultural tem por base a caracterização do ambiente doméstico estatal como o lugar da harmonia, da legitimidade da violência e da presença de congruências valorativas e culturais. É o apagamento das distensões e conflitos no interior do Estado que possibilita a noção de uma anarquia internacional. Enquanto o ambiente doméstico é caracterizado por um suposto consenso a respeito das regras que regem as ações dos agentes no interior do Estado, $\mathrm{o}$ ambiente internacional pode ser visto na maior parte das vezes como o lugar do dissenso e, portanto, da ausência de regras que regulem as ações.

Este processo de delineação dicotômica espacial é acompanhado pelo centramento das atençōes no Estado e nas categorias ocidentais de ausência/ presença. As narrativas seculares da modernidade reificam a ontologia do Estado soberano e dimensionam a noção de "internacional" por meio de redes de inclusão e exclusão, centros e periferias. 
Questões sobre soberania são especialmente proeminentes em debates sobre "mudança", sobre histórias, futuros e temporalidades: debates amplamente organizados por afirmaçōes sobre presença e ausência temporais de espaços soberanos articulados e suas fronteiras espaciais. Quanto mais a soberania é discutida nesse contexto, entretanto, mais um relato específico sobre o que soberania deve ser é reproduzido em detrimento de possíveis alternativas (Walker, 2010, p.150, tradução nossa).

\section{Walker e as noçóes de tempo e espaço}

Segundo Walker (1995), a política contemporânea é caracterizada por processos de aceleração temporal e consequente deslocamentos espaciais. Esse encurtamento das extensóes de tempo acaba gerando incongruências entre as noções de espaço do ambiente internacional que, por sua vez, refletem essas contradições a partir de novas articulações de poder e a necessidade de novos parâmetros para a compreensão dos limites temporais.

Os tradicionais conceitos de fronteira tornam-se limitados para a compreensão das novas relações de tempo. Entretanto, as demandas por novos paradigmas não são atendidas de imediato. A distância entre as movimentações temporais e a adoção de novos conceitos sobre espaço geram cisões na lógica de análise das Relaçōes Internacionais, fazendo com que tradicionais concepções de fronteira e dicotomias entre o ambiente internacional e doméstico tenham de conviver com a arbitrariedade das suas divisões. O conceito de soberania estatal não consegue mais abordar novas demandas que perpassam as fronteiras espaciais, no seu sentido tradicional. O apagamento dessas contradições, que potencialmente desconstruiriam o campo do internacional, torna-se estratégia crucial de sobrevivência dessas delimitaçôes. Sem a aceitação da noção de que existe algo dentro e fora dos Estados, as Relações Internacionais não teriam razão de existir como campo à parte das ciências políticas:

Esta resolução expressa na alegada soberania estatal é condição crucial que permite e enco- raja a distinção constitutiva entre duas tradições de pensamento e análise da vida política moderna: a tradição do pensamento político propriamente dito, de um lado, e a tradição das teorias de Relações Internacionais, de outro. Essa distinção entre dentro e fora, quando feita explicitamente, como é usual na teoria de Relações Internacionais, ou mesmo tacitamente, como é usual em textos sobre teoria política, continua a informar nossa compreensão a respeito de como e quando práticas políticas efetivas e progressivas podem ser desenvolvidas (Idem, p. 13, tradução nossa).

Assim, dois níveis de análise são produzidos. De um lado, a noção de espaço como fundadora do conceito de "internacional". A atemporalidade da anarquia e a noção que caracteriza o "internacional" como um lugar, e não como um momento, possibilitando a visão de relações entre atores internacionais como ações que se justificam por sua localização. É no exterior que a estrutura, em seu sentido atemporal, pode ser responsabilizada pelas açôes dos agentes. De outro lado, a noção de tempo fornece suporte à vida na pólis, ou seja, no interior do Estado. Enquanto o lugar do "internacional” é constituído por limites espaciais, o âmbito do doméstico seria resultado de articulações no tempo cristalizadas na forma da vida política no interior das unidades estatais.

Esta dicotomia entre tempo e espaço teria reflexos práticos na análise das relaçôes internacionais. Uma vez que o ambiente doméstico é caracterizado pela homogeneidade e por uma suposta concordância entre os cidadãos sobre a ação dos agentes estatais, tem-se a possibilidade de construir exigências éticas sobre o comportamento dos seus atores. $\mathrm{O}$ apagamento das distensōes sociais e o silêncio a respeito do privilégio de determinados grupos dentro do Estado geram a legitimação das práticas que ocorrem no seu interior (Idem). Já no ambiente externo, internacional, a suposta ausência de hegemonia cultural e a falta de uma instância centralizada e legítima que garanta os padrões de comportamento acabam gerando a impossibilidade de qualquer cobrança ética em relação às ações dos agentes internacionais. 
Uma vez que se parte dessa metáfora, as condições sob as quais ações éticas poderiam ser encontradas no espaço exterior aos Estados já estariam por si limitadas:

A disjunção entre ética e relações internacionais reflete o cisma entre comunidade e anarquia, progresso temporal e contingência geopolítica, política e relações. Enquanto espaços políticos continuam articulados dessa maneira, pode-se dizer que a disjunção entre ética e relações internacionais deve continuar um lamentável e até mesmo trágico fato da vida (Idem, p. 64, tradução nossa).

A divisão entre o que acontece dentro e fora dos Estados, com a pressuposição das suas respectivas características, já revelaria, em princípio, o caráter de excepcionalidade de qualquer teoria que tentasse demonstrar que no ambiente internacional há regras compartilhadas. Desse modo, mesmo as teorias que têm por objetivo relativizar os princípios do paradigma realista, no que se refere à impossibilidade de ética no campo das Relaçôes Internacionais, estariam já limitadas pelo pressuposto da infertilidade desse espaço externo em desenvolver esse tipo de relação.

Assim, relativizar a lógica do paradigma realista sem desconstruir a metáfora fundadora dos seus princípios e as condições essenciais de sua existência significaria, no máximo, relativizar um cenário que, por si, não permite subverter a lógica que o funda. Para Walker, mesmo as teorias de contraponto ao realismo partem, em sua maioria, da mesma metáfora que constrói e sustenta a possibilidade dicotômica entre um ambiente doméstico e outro internacional. A abordagem radical, nessa perspectiva, somente poderia ser alcançada uma vez desconstruídos os pilares de origem da divisão espacial. Enquanto não se revelar alternativas à lógica insideloutside, as respostas possíveis às perguntas formuladas por essa metáfora já estarão sempre dadas. Em outras palavras, enquanto o campo de conhecimento das Relações Internacionais continuar fundado na divisão entre aquilo que se encontra dentro ou fora dos Estados, as possibilidades de conduta ética e comportamento político desse lado de fora sempre serão limitadas.
Não se trata, entretanto, de negar, em termos tradicionais, a perspectiva fundadora do campo das Relaçôes Internacionais. O que Walker pretende no seu discurso é chamar a atenção para a necessidade da presença de pressupostos arbitrários que possibilitam a gênese da noção de um espaço construído em contraposição àquele espaço tradicionalmente vinculado à política. Uma vez que esses pressupostos são rompidos, teríamos a necessária desconstrução do próprio conceito de "internacional".

Outras perspectivas advindas dessa desconstrução, entretanto, não deveriam ser julgadas necessariamente com base em parâmetros hierarquizantes fundados na proximidade com uma suposta realidade. A alternativa à perspectiva tradicional não deve ser considerada como melhor em termos absolutos, quando comparada à usual dicotomia insideloutside. O que se tem à frente é única e simplesmente a abertura de espaço para a ampliação das possibilidades discursivas sobre as relações internacionais e, sobretudo, a revelação das premissas sobre as quais se assentam os discursos tradicionais. Com isso, seria possível trabalhar sob novas perspectivas, o que permitiria encontrar respostas até então inviabilizadas pelos pressupostos sob os quais se assentam os conhecimentos atuais, principalmente no que se refere à busca de padrões éticos no ambiente internacional. O trabalho de Walker é muito mais o de revelar as condições de construção de um discurso sobre o "internacional" do que de apresentar a melhor alternativa a esse discurso. A indicação da arbitrariedade fundadora da dicotomia entre os dois ambientes objetiva mais uma abertura na estrutura que limita a reflexão sobre o "internacional" do que propriamente sugerir novas abordagens no sentido de classificar o que deve ser considerado certo ou errado. ${ }^{5}$

Ler teorias de Relações Internacionais dessa maneira, eu já sugeri, significa entendê-las menos como uma explicação do mundo político contemporâneo do que como uma expressão do processo que elas alegam explicar. Como tal, procurei questionar os pressupostos, as reificações e as estratégias textuais da teoria das Relações Internacionais, não porque espero contribuir para uma melhor explicação teórica, pelo menos 
não sobre as relações internacionais, mas com o intuito de problematizar horizontes teóricos e práticos que continuam sendo entendidos como dados (Idem, p. 159, tradução nossa)

\section{A relatividade da relatividade}

A estratégia de Walker, entretanto, também é delimitada por suas possibilidades e, assim como qualquer perspectiva de mundo, assenta-se sobre determinado patamar de arbitrariedade. ${ }^{6}$ Uma vez que o ambiente internacional só é possível a partir de uma divisão espacial, sendo que o lugar fora do Estado pressupooe-se ausente de história, isto é, da noção de tempo, devemos notar que é apenas pela separação entre tempo e espaço que essa crítica se sustenta e gera abertura para a desconstrução da dicotomia que funda o "internacional".

Segundo Walker (1995), o principal ponto da sua crítica gira em torno das novas possibilidades de articulação entre as noções de tempo e espaço. Assim, como o mundo contemporâneo está cada vez mais caracterizado por processos de aceleração temporal, é comum que encontremos alguma incongruência entre as noções de tempo e espaço que informam e dão sentido ao mundo em que vivemos. A manipulação dessas relações por meio de jogos de poder, portanto, teria a capacidade de produzir discursos a partir dessas incongruências sem que sua contradição fosse percebida pelo receptor desse conhecimento. Discursos disciplinares estariam encarregados de apagar todas as contradições e relativizações históricas em nome de uma suposta neutralidade embasada na atemporalidade e, também, em prol de uma suposta uniformização discursiva, que passaria a ideia de coerência dentro do campo de conhecimento.

O que não se discute, entretanto, são as condições em que essa crítica é possível. Uma vez que o perspectivismo de Walker utiliza a noção de tempo e espaço, no sentido histórico e geográfico, para denunciar a arbitrariedade das afirmaçōes sobre o "internacional", o mesmo poderia ser feito em relação ao discurso alternativo que subverte esse paradigma. ${ }^{7} \mathrm{~A}$ intencionalidade anunciada do autor em não negar a tradição, e sim mostrar as condi- ções históricas sobre as quais ela foi edificada, não significa que a nova visão oferecida não contenha também um caráter político. ${ }^{8} \mathrm{~A}$ pós-modernidade, principalmente aquela que radicaliza as consequências da virada linguística, caracterizou-se sempre pela impossibilidade de negação absoluta de paradigmas, uma vez que a adoção de tal estratégia significaria a admissão de critérios criados pelo próprio fenômeno negado. Assim, dizer que o conhecimento produzido até então não é correto significaria aderir a um paradigma que separa o certo do errado, a verdade da mentira.

A saída para esse dilema foi revestir toda a argumentação contemporânea com o véu das possibilidades e moldar todo discurso de crítica com a anunciada pretensão de somente ampliar o leque de opções e mostrar condiçôes pelas quais determinados discursos puderam ser produzidos. Entretanto, a ampliação das visões de mundo repousa, em princípio, entre dois dilemas. Primeiro, a sempre presente possibilidade de os critérios discursivos utilizados para determinada crítica serem também conduzidos contra o crítico que os produz. Assim, uma vez que se prega a arbitrariedade do conhecimento tradicional, por meio de uma relativização das suas possibilidades, o mesmo poderia ser dito sobre esse discurso perspectivista. $\mathrm{O}$ risco de se cair em um niilismo improdutivo faz com que a própria crítica se proteja, afirmando de antemão que não é sua intenção negar em termos absolutos a tradição, e sim fornecer olhares alternativos a ela, a partir da demonstração das arbitrariedades que a produziram. ${ }^{9}$

Segundo, visto que a fuga dessa possibilidade niilista se verifica, o discurso pós-estruturalista utiliza o expediente de ampliar tão somente as possibilidades em que novos discursos podem ser produzidos. Como se a ampliação das opções fosse, por si mesma, ausente de interesses. Dessa forma, o caráter do arbitrário é ressaltado em relação à tradição que sustenta o saber em determinado campo de conhecimento, ao mesmo tempo que os discursos pós-estruturalistas enfatizam como principal objetivo a ampliação das possibilidades, em vez de inverter a lógica já conhecida. Como em um jogo de espelhos, os autores tentam desconstruir determinados fenômenos sem deixar que a desconstrução atinja a própria crítica. 
Entretanto, qualquer tipo de crítica mais tradicional somente é possível através da dicotomia de determinadas lógicas. O que está em jogo aqui é o que se entende por crítica. Se utilizado no sentido de contraposição, o discurso crítico sempre terá a possibilidade de ser reconfigurado, deixando de ser autor do ataque para virar seu alvo. No entanto, uma vez que a crítica abandone o sentido de contraposição e assuma um caráter perspectivista, ela conseguirá romper com paradigmas, já que desconstruirá não a argumentação que se tem como alvo, mas os critérios de legitimação que o sustentam.

No caso do campo de Relações Internacionais, portanto, a radicalidade crítica desenvolvida até então não estaria na contra-argumentação ao paradigma realista, ou a qualquer alternativa que relativize essa posição, e sim na adoção de perspectivas que não se encontram incluídas no arcabouço considerado legítimo para sua sustentação teórica. Entretanto, pelo fato de essas críticas utilizarem, ainda que de forma alternativa, as próprias noções históricas sobre as quais se assentam o discurso da arbitrariedade das perspectivas, chegamos à conclusão de que, apesar de contundente, essa estratégia ainda não significa rompimento radical com o paradigma, mas o reposicionamento das categorias sobre as quais o discurso foi (re)produzido. ${ }^{10}$

Se observarmos a estratégia utilizada por Walker, podemos verificar que a relativização efetivada pelo posicionamento das possibilidades históricas não significa total desconstrução da noção de história como algo linear. ${ }^{11}$ A rearticulação das relaçôes entre tempo e espaço, mesmo que essas variáveis binárias sejam consideradas como dialeticamente constitutivas, não abandona a possibilidade de se visualizar uma dessas variáveis sem a necessidade de se pressupor a outra de forma tácita. Desse modo, o conceito de negação, na sua forma mais radical, não estaria na inversão da lógica do discurso produzido. Também não estaria na ampliação das possibilidades discursivas, nem na relativização de paradigmas por via da apresentação das condições históricas sobre as quais se assentam, mas na adoção de critérios que neguem a lógica formal, no sentido de primeiro ser possível discutir a possibilidade da não contradição para, somente depois, posicionarmos discursivamente determinadas perspectivas.

\section{Desconstrução e tresvaloração}

Um dos principais instrumentos utilizados por autores pós-estruturalistas é a já aludida desconstrução, estratégia elaborada por Derrida como possibilidade crítica às noções estruturais. A própria lógica da desconstrução impossibilita uma definição objetiva desse conceito. Seguindo a tradição nietzschiana, Derrida entende todo esforço de delimitação conceitual como algo sempre fadado à incompletude, uma vez que a busca de interpretações objetivas nos leva apenas a gerar outras interpretações. Conceituar seria justificável mais pelo processo em si do que pelos objetivos almejados. Por outro lado, a dificuldade em torno desse conceito não impossibilita apontar o que não deve ser considerado como tal. ${ }^{12} \mathrm{~A}$ desconstrução seria, assim, uma abordagem que se define pela negação. Só teremos ideia do que seja desconstruir quando há clareza daquilo que não se refere a esse conceito.

Não é fácil definir "desconstrução" [...]. Como sugere o próprio Derrida, criador da palavra e iniciador de um tipo de reflexão que tem agitado os círculos intelectuais da Europa Ocidental e dos Estados Unidos há quase duas décadas, talvez seja mais adequado dizer o que não é "desconstrução": não é um método, nem uma técnica e nem tampouco um modelo de crítica que possa ser sistematizado e regularmente aplicado a teorias, textos ou conceitos (Arrojo, 1992, p. 9).

Em primeiro lugar, não é possível haver desconstrução absoluta. A própria possibilidade de se denominar algo passível de ser desconstruído gera a necessidade de algum ponto de referência (mesmo que negativo) a partir do qual o que está sendo desconstruído possa ser julgado. Relativizar ao infinito significaria, nessa lógica, a impossibilidade de relativização, pois, se tudo é relativo, as coisas seriam relativas em relação a quê? Portanto, o projeto derridiano também deve ser inserido em uma radicalidade limitada por suas próprias condições de existência. Desconstruir, assim, significa não negar por completo o que se quer relativizar, mas aceitar até certo ponto o que está dado para, a partir daí, ressignificar o fenômeno. ${ }^{13}$ Coerente com 
essa lógica, Derrida aceita a visão de realidade binária, ao menos até o ponto de poder desconstruí-la. Segundo o autor, a noção de realidade sempre foi criada tendo-se em vista dicotomias que, por oposição, criam a noção do que seja ou não verdadeiro.

O pensamento ocidental, de acordo com Derrida, sempre foi estruturado por dicotomias ou polaridades, como bom/mau, presença/ausência, verdade/erro, identidade/diferença, natureza/cultura, fala/escrita. Esses opostos não são nem iguais em valores, nem independentes uns dos outros. Mais que isso, como Barbara Johnson explica, o "segundo termo em cada par é considerado o negativo, corrupto, indesejável versão do primeiro, uma degenerescência daquele”. Então, a oposição implica uma ordem hierárquica. $\mathrm{O}$ primeiro termo é temporal e qualitativamente prioritário. "Em geral, o que as oposições hierárquicas fazem é privilegiar a unidade, a imediaticidade e a presença temporal e espacial sobre distância, diferença e simulação e deferimento". ${ }^{14}$ A filosofia ocidental sempre caracterizou o ser ou "real" como presença (Zehfuss, 2002, p. 197, tradução nossa).

Assim, Derrida não se propõe a negar as dicotomias criadas pela filosofia tradicional. Contudo, chama a atenção para o fato de que toda dicotomia parte de pressupostos valorativos, segundo os quais um dos termos de uma polaridade é considerado sempre superior ao outro. Desconstruir, então, significaria deslocar a dicotomia, dando maior peso àquela polaridade menos valorizada. ${ }^{15} \mathrm{Em}$ vez de repetir o erro inicial, a valorização daquilo que é periférico geraria um descentramento estrutural, fazendo com que a noção de presença fosse substituída pela noção de ausência. Assim, o sentido de um fenômeno, em vez de ter sua lógica invertida, seria exposto às suas próprias contradiçôes, gerando a instabilidade de sua coerência, já que a arbitrariedade dos valores dados se revelaria. De acordo com Barnett, citando Derrida:

Desconstrução não suplanta uma gama de conceitos por uma gama completamente nova. Ela suplanta conceitos existentes. Desconstru- ção "libera" características do conceito que são normalmente mantidas em reserva e as estende para além de seus escopos normalmente restritos. Fazendo isso, ela atenua os claros limites que sustentam suas restrições (Barnett, 1999, p. 284, tradução nossa).

A noção de sentido somente seria possível a partir da repetição do diferente que se quer o mesmo. Derrida cunha o termo différance como um neografismo que revela a possibilidade de se ter um elemento gráfico que escapa das possibilidades fonéticas. Différance seria o intricado jogo de perspectivas que gera sentidos de forma contínua, sem nunca se prenderem a um sentido fixo. Trata-se de um processo constante de relacionar sentidos a determinados signos que, por sua vez, estariam sempre em fuga. Assim, a noção de presença somente seria compreendida pela ideia de ausência. É o não ser que proporciona a ilusão do ser em um constante jogo de ressignificações. Desse modo, a repetição do diferente que se supõe igual é que construiria a noção de realidade. Existir é repetir-se constantemente em um fluxo que busca estabilizar incongruências por meio de valorações. ${ }^{16}$

Portanto, caso se faça a opção por uma crítica no sentido tradicional, estaríamos apenas reforçando o próprio sistema que se quer desconstruir. Insistir em apontar o contraditório só reforça a identidade e reafirma a possibilidade de uma presença e verdade absolutas. Desconstruir seria reafirmar aquilo a que se contrapõe. Partindo do pressuposto de que a estabilidade da estrutura é formada por incoerências, e de que toda noção de presença é transitória, somente a repetição à exaustão seria capaz de esgarçar os feixes de sentidos produzidos por uma centralização da estrutura. Desconstruir é não centralizar, não se opor, não aceitar e, por fim, não reproduzir o diferente. A desconstrução descentraliza a lógica estrutural, denunciando a presença de aberturas através das quais os significados escoam em busca de novas relações, gerando a sensação de que só é possível existir o mesmo a partir da transformação. "Eis por que a ideia de herança implica não apenas reafirmação e dupla injunção, mas a cada instante, em um contexto diferente, uma filtragem, uma escolha, uma estratégia" (Derrida, 2004b, p. 17). 


\section{Desconstrução e repetição}

A posição de Derrida como um autor pós-estruturalista acompanha a lógica segundo a qual o prefixo "pós" não designa negação absoluta do conceito de estrutura, e sim uma superação daquilo que ele adjetiva. Caso se fixasse como simples negação das tradições estruturalistas, o pós-estruturalismo estaria repetindo a lógica de tudo o que, em princípio, tenta relativizar. Pelo próprio fato de o pós-estruturalismo denunciar os critérios binários de exclusão - como, por exemplo, a dicotomia verdade/mentira -, Derrida não poderia negar objetivamente as abordagens estruturais. Fazê-lo seria inserir-se por completo na própria lógica daquilo que se quer superar.

Portanto, o pós-estruturalismo derridiano não busca se contrapor em termos absolutos às abordagens sistêmico-estruturais, mas ir além delas sem as abandonar por completo. Trata-se de inverter a lógica tradicional do conceito de estrutura a partir de suas próprias premissas. Para Derrida, a única opção que não o levaria a repetir aquilo que se nega seria a utilização das mesmas armas dadas pelas abordagens que se quer questionar. Assim, o desafio imposto ao autor seria o de ir além do estruturalismo a partir de estratégias até então criadas por essa mesma abordagem.

Com efeito, e para o desespero total daqueles que ainda lhe resistem, a desconstrução se apresenta como nada além do próprio estruturalismo levado às suas últimas consequências. Isto é, como o que pode ser visto como o mais intrigante de todos os paradoxos, o desconstrutivista revela ser, no fundo, um estruturalista que leva a sua empresa com um empenho e dedicação que os próprios estruturalistas praticantes e inveterados não foram capazes de mobilizar. Ele os desafia e os incomoda ao insistir em convidá-los a serem estruturalistas até o fim como ele e a assumirem a sua fé na plenitude de suas consequências. A desconstrução não aborda o estruturalismo do lado de fora; ela o faz de dentro, trabalhando com o próprio instrumental que o estruturalismo forjou (cf. Hutton, 1989, p. 75) (Rajagopalan, 1992, p. 26).
Nessa perspectiva, assim como o estruturalismo, o pós-estruturalismo aceitaria, em princípio, a possibilidade de se explicar os fenômenos da realidade a partir da sua abstração em estruturas lógicas. Entretanto, ao contrário do estruturalismo, que considera a sustentabilidade das estruturas lógicas gerada pela coerência dos termos e pressupostos que a compõem, o pós-estruturalismo chamaria a atenção para o fato de toda estrutura somente se sustentar a partir de contradiçôes. Uma vez que o significado gerado a partir de um fenômeno, ou conceito, só se torna apreensível a partir do seu oposto, a própria existência da unidade teria como base a sua negação. ${ }^{17}$ Aquilo que na superfície aparenta uma coerência intrinsecamente lógica, segundo o pós-estruturalismo, somente o seria a partir do momento em que as contradições de seus termos sejam apagadas.

Por outro lado, apesar de essas contradições que formam as bases das estruturas poderem ser ignoradas por certo tempo, possibilitando a formação de um sentido superficial sobre determinado fenômeno, elas não deixariam de gerar uma constante tensão, que acabaria por corroer o significado mais geral da estrutura. Neste ponto, é importante ressaltar que: (1) a unidade lógica das estruturas somente ganha sentido a partir das suas contradiçôes. É o apagamento do não lógico que gera a sensação de unidade e sentido a toda estrutura; (2) a própria existência de um fenômeno só se sustenta no tempo pela repetição de seus significados. Assim, é a constante afirmação daquilo que é contraditório que possibilita a formação de um sentido considerado lógico.

Essa constante necessidade de afirmação do contraditório para gerar coerência estrutural acaba, contudo, ressaltando as tensões existentes entre os termos que compõem as próprias estruturas. Com o excesso de repetição, a sustentação da lógica superficial das estruturas não resistiria à pressão conceitual de termos incompatíveis e acabaria gerando um processo de erosão da própria lógica. Isso significa que, apesar de ser possível para os pós-estruturalistas explicar e dar sentido aos fenômenos a partir de abstraçôes estruturais, tais abstrações teriam que, mais cedo ou mais tarde, enfrentar o inevitável: toda estrutura é instável, e essa instabili- 
dade é gerada pela repetição incessante daquilo que gera sua unidade, a contradição conceitual.

Desse modo, tentando gerar um sentido constante e estabilizar as interpretaçóes estruturais dos fenômenos, os processos de explicação estrutural acabariam provocando sua própria ruína. $\mathrm{O}$ resultado dessa implosão do sentido pela repetição seria a geração de novas estruturas que, nascidas a partir de resquícios da anterior, também seriam sustentadas por novas contradições passíveis de implosões conceituais criadas pela constante repetição do sentido. Nessa lógica, a negação radical de determinada perspectiva não estaria no contraponto à mesma, mas na repetição à exaustão dos seus enunciados, que acabaria por gerar um excesso de tensão nas contradições que sustentam essa perspectiva e a desconstruiria pela instabilidade advinda desse processo. É repetindo o diferente que se desconstrói aquilo que se afirma.

A desaparição da face ou a estrutura de repetição não se deixam, pois, dominar pelo valor de verdade. A oposição do verdadeiro e do não verdadeiro está, ao contrário, inteiramente compreendida, inscrita nessa estrutura ou nessa escritura geral. $\mathrm{O}$ verdadeiro e o não verdadeiro são uma espécie de repetição. E só há repetição possível no gráfico da suplementaridade, acrescentando, na falta de uma unidade plena, uma outra unidade vem supri-la, sendo ao mesmo tempo a mesma o bastante e outra o bastante para substituir acrescentando. Assim, por um lado, a repetição é isso sem o que não haveria verdade: a verdade do ente sob a forma inteligível da idealidade descobre no ềdos o que pode se repetir, sendo o mesmo, o claro, o estável, o identificável em sua igualdade a si. E apenas o eîdos pode dar lugar à repetição como anamnésia ou maêutica, dialética ou diática. Aqui a repetição se dá como repetição de vida. A tautologia é a vida só saindo de si para voltar a entrar em si. Mantendo-se junto a si na mnéme, no lógos e na phoné. Mas, por outro lado, a repetição é o próprio movimento da não verdade: a presença do ente perde-se nele, dispersa-se, multiplica-se por mimemas, ícones, fantasmas, simulacros etc. Por fenô- menos, desde então. E esta repetição é a possibilidade do devir sensível, a não idealidade. Do lado da não filosofia, da não memória, da hipomnésia, da escritura. Aqui a tautologia é a saída sem retorno da vida fora de si. Repetição de morte. Despesa sem reserva. Excesso irredutível, pelo jogo do suplemento, de toda intimidade a si do vivo, do bem, do verdadeiro (Derrida, 2005b, p. 122).

\section{O paradigma realista e a desconstrução pela (re)afirmação}

As abordagens pós-estruturalistas do campo das Relaçôes Internacionais têm como objetivo a radicalização das críticas às teorias mais convencionais por meio do questionamento dos elementos que produzem suas sustentaçōes. A obra de Robert Walker (1995) propõe a desconstrução desse campo de conhecimento, denunciando a arbitrariedade da dicotomia insideloutside. A tresvaloração dessas polaridades revelaria os limites impostos pela sua própria aceitação. Essa estratégia pós-estruturalista, entretanto, deveria sempre se esquivar de dois perigos inerentes a qualquer radicalidade crítica: a possibilidade de a relativização proposta por esses autores atingir o próprio processo de desconstrução e a necessidade, intrínseca à lógica pós-estrutural, de proteger seu próprio arcabouço lógico pela negação de uma hierarquização de perspectivas e pela enunciação dessa nova abordagem crítica como apenas uma ampliação das possibilidades na produção de saber sobre o "internacional". Assim, as consideraçôes de Walker estariam limitadas à sua própria condição de existência. Para que os conceitos de inside e outside fossem passíveis de relativização, as noções tradicionais de tempo e espaço, necessariamente, precisariam ser mantidas. ${ }^{18}$ Simultâneos a essa estratégia, os objetivos da abordagem também tiveram de ser limitados a uma proposta de simples ampliação das possibilidades, uma vez que qualquer tentativa de valoração das novas perspectivas produziria uma perda da capacidade crítica por adotar critérios do paradigma questionado.

A manutenção de referências fixas em uma análise pós-estrutural representa uma necessidade 
intrínseca à própria desconstrução. Como já discutido, somente é possível relativizar um fenômeno a partir do momento em que determinados aspectos continuem intocados, pois, para que a noção de mudança seja percebida, algo precisa ser entendido como fixo. Entretanto, seguindo a própria lógica da desconstrução derridiana, é preciso que toda crítica produzida esteja sempre em constante processo de radicalização, para que os efeitos verificados em um primeiro momento possam manter sua intensidade. Assim, uma vez que as abordagens mainstream das Relaçōes Internacionais passaram por um processo de contextualização do adjetivo "internacional" e que a dicotomia insideloutside foi denunciada como arbitrária, restaria elaborar novas formas de críticas que pudessem continuar a desconstruir esse campo de conhecimento em um constante processo de reelaboração do saber. ${ }^{19}$

A nova radicalidade possível em relação às abordagens tradicionais do "internacional" não poderia ser encontrada mais na sua contestação tradicional, já que, segundo a lógica derridiana, o contraponto geraria mais reforço que relativização daquilo que se quer desconstruído. Também a relativização através da contextualização temporal não possuiria mais a intensidade inicial, uma vez que o processo de relativização através da história e do contexto já passa a ser aceito como uma perspectiva factível de ser aplicada a qualquer fenômeno. O passo seguinte, portanto, seria a produção de uma radicalidade mais imprevisível. Ao contrário do confronto e da relativização, a negação das teorias mais tradicionais do campo das Relações Internacionais estaria na sua própria reafirmação. Uma repetição que, devido à própria intensidade, acabaria por anular sua força explicativa, fazendo com que o esgotamento do seu opositor seja operado a partir do próprio recurso à sua lógica. Visto que todas as estruturas explicativas são instáveis e sustentadas por incoerências, sua desconstrução somente seria possível, agora, através de demandas às suas capacidades analíticas. Os limites que produzem as tensões necessárias à manutenção da unidade teórica seriam desfeitos, pois o contraponto deixaria de existir. Fenômenos que se formam pela diferenciação em relação às demais possibilidades não se sustentam na ausência destas. No caso do neorre- alismo, por exemplo, somente uma sobredemanda em seu arcabouço teórico geraria uma radicalização crítica suficiente para que sua capacidade de explicação se extinguisse.

Uma vez que o neorrealismo se concentra no papel da estrutura para explicar o comportamento das unidades, uma crítica atual, mais radical, estaria na reafirmação desse conceito, forçando-o a explicar todo o fenômeno do "internacional". O reforço da ideia de estrutura geraria uma sobrecarga de significantes sobre ela, fazendo com que o próprio conceito não suportasse sua lógica. Se a intenção inicial do neorrealismo era mover por um momento o foco das unidades e transferi-lo para o sistema, caso essa lógica fosse levada até as últimas consequências, o conceito de estrutura não conseguiria sobreviver às suas contradições. $\mathrm{O}$ foco que havia sido transportado das unidades para o contexto seria reafirmado até perder a própria nitidez. A tensão existente entre o papel das unidades e o papel da estrutura seria catalisada a ponto de o próprio modelo ser desconstruído. A relação dialética - por meio da qual a unidade cria a estrutura que, por sua vez, é responsável pela noção de unidade - somente se sustenta na superficialidade. Estando o centro é deslocado, o que exige que a estrutura dê conta não somente do comportamento das unidades, mas também de sua própria criação, a noção de fenômeno encontraria sua abertura.

Essa estratégia adotada evitaria duas possibilidades enfrentadas por abordagens mais clássicas: na medida em que a inversão da lógica afirmada está sendo trocada pela própria reafirmação dessa lógica (nesse caso a lógica da estrutura do neorrealismo), a crítica não precisaria responder à sua própria inversão. A relativização da abordagem estrutural terá sido feita reafirmando a própria abordagem. Não se trata de negar algo, mas de exigir uma carga de coerência a um conceito que, como todos os outros, não se fecha por completo. Por outro lado, ao abrir mão do processo de genealogia e arqueologia que, até certo ponto, consegue relativizar a tradição em questão, estaríamos, também, evitando a adoção de categorias historicamente conservadoras. A própria noção de possibilidade temporal contém como pressuposto a ideia de evoluçãa, mesmo que não no sentido tradicional. A relação tempo/espaço 
deixa de ser um campo de possibilidades combinatórias sobre as quais seja possível fazer relativizaçôes e passa a ser uma categoria dispensável, pois a reafirmação daquilo que se nega não necessita da relação entre essas variáveis.

\section{O artista da fome e a estrutura do espetáculo}

O artista da fome de Kafka é apenas uma das partes que formam o espetáculo. Sem a presença do público que o observa, a condição do artista da fome poderia ser resumida a uma insanidade individual ou à constatação de uma mendicância que se instaura pela simples falta de alternativas. O fim último do conto não está centrado na situação do famigerado, nem no interesse mórbido dos que o observam. O todo deve ser julgado pela relação entre as partes. $\mathrm{O}$ centramento em qualquer uma das perspectivas - artista, público ou situação - roubaria o sentido do espetáculo. É a contradição da luta pela sobrevivência que gera o interesse na apresentação. É a tentativa de manter-se vivo através da morte lenta que constrói o sentido do ritual. É o contraponto àqueles que não passam fome que gera a singularidade do espetáculo. A fome do jejuador não é produto das circunstâncias, mas a própria autora da situação.

Qualquer tentativa de negar esse modo de se ganhar a vida esbarraria nos limites construídos pelo próprio contexto. Querer salvar o artista da fome dando-lhe o que comer é matá-lo. Tentar garantir-lhe o sustento com a manutenção desse emprego também significaria a sua morte. Uma outra ocupação para o protagonista significaria ausência do problema e, portanto, não faria mais sentido encontrar a resposta. $\mathrm{O}$ contraponto àquilo a que se assiste estaria simplesmente na sua afirmação. A única saída para o artista dessa estrutura cíclica estaria no aumento da intensidade da sua própria trama. Intensidade que deve ser suficiente para transformar as contradições em aspectos insustentáveis pela própria estrutura. A contradição do conto é que baliza o espetáculo. $\mathrm{O}$ contexto de fome constrói a tragédia. Entretanto, é seu encobertamento que dá sentido ao enredo. Se a fome sentida pelo ator fosse compreendida a partir do contexto e não da vontade do artista, sua lógica não se sustentaria. Qualquer indivíduo no lugar do artista seria protagonista do espetáculo não por dom, mas pela absoluta falta de alternativa. $\mathrm{O}$ discurso que informa ser o espetáculo produto da vontade do jejuador em mostrar suas habilidades esconde a completa falta de opção daquele homem. A força do espetáculo não consegue sobreviver à falta de alternativas encontrada pelo artista.

Se hoje o circo medieval não faz mais sentido é porque a estrutura que o mantinha perdeu seu centro. As aberrações que séculos atrás eram consideradas dignas de se observar não chamam mais a atenção por falta de sentido do ser. Se qualquer indivíduo, nas mesmas circunstâncias, fizesse o mesmo, o espetáculo já não possuiria atrativos. No circo medieval era o desejo de se mostrar do artista que fascinava o olhar. Com o fim da vontade do sujeito, que deixa de ser autor e se torna apenas centro da estrutura, termina também o feixe de significados do fenômeno. Mostrar a verdade daqueles artistas através do discurso sobre a estrutura da sua condição significa rebaixar a tensão dos sentidos. $\mathrm{O}$ foco na estrutura da cena significa mostrar a contradição do espetáculo. Esse deslocamento faz o artista ser ao mesmo tempo centro e periferia. Centro das atençôes, mas sempre à margem da estrutura. Ninguém está mais diante do improvável; pelo contrário, a apresentação do artista passou a ser encarada não a partir da perspectiva de um autor que produz o contexto, mas de um contexto que produz o autor. Um processo interminável de repetiçôes que, se em princípio gerava significado ao espetáculo, com o tempo acabou por desestabilizar qualquer possibilidade de significação. Um contexto no qual a repetição do diferente era chamada a gerar continuamente a presença do mesmo. Nenhuma estrutura resiste a tamanha responsabilidade.

\section{Notas}

1 O autor mais exemplar desse grupo é Wendt, que, sem abandonar a noção de estrutura, considera-a mais como produto do compartilhamento de ideias do que da distribuição material de poder. Ainda de acordo com esse autor, ao contrário das abordagens 
neorrealistas, que restringem suas análises ao estudo do impacto da estrutura no comportamento das unidades, Wendt considera que essa estrutura também influencia a constante construção e reconstrução das identidades estatais (Wendt, 2003).

2 Além dessas abordagens, podemos citar, também, autores da Teoria Crítica. Esta não será abordada no presente artigo, a despeito da sua importância para os atuais debates em Relações Internacionais, devido à distância que ela se encontra em relação às críticas pós-estruturalistas, objeto do presente estudo.

3 Neste trabalho, considera-se que a tradição estruturalista, apesar de se expandir somente a partir da segunda metade do século XX, tem suas bases na linguística de Saussure. Este autor, apesar de não trabalhar diretamente com o conceito de estrutura, desenvolveu abordagens sistêmicas que podem ser consideradas protoestruturalistas (Mussalim e Bentes, 2006).

4 Para a relação entre classificações e produções de saber, ver Foucault (2004b).

5 Isto não significa dizer que, segundo Walker, a hierarquização de perspectivas não seja possível. $\mathrm{O}$ autor afirma ser possível distinguir entre uma boa e má abordagem. Entretanto, as alternativas chegam a um limite que seria superado apenas pela desconstrução de determinados pressupostos (Walker, 1995).

6 Isto não significa que o autor não se dê conta disso. Até certo ponto, a crítica feita pelos pós-estruturalistas no sentido de apontar condiçôes sobre as quais se assenta a produção de conhecimento ocidental necessita ser limitada às próprias categorias do pensamento ocidental.

7 Em sua obra de 2010 After the globe, before the world, o autor dá sequência aos argumentos desenvolvidos no livro Insideloutside. Desta vez, Walker trabalha com novas noções espaço-temporais com foco na complexidade das periferias e fronteiras, mas ainda se atém às categorias da tradição do pensamento anglo-americano.

8 Talvez seja esse um dos motivos pelo qual o autor prefere trabalhar com o conceito de tempo, e não de história, que, segundo ele, vem sendo utilizado pelas visôes mais conservadoras no sentido de historicismo (Walker, 1995).

9 Essa possibilidade de crítica já era reconhecida desde os escritos de Nietzsche, sobre os quais se alegava que as relatividades das interpretaçōes apontadas pelo autor poderiam ser utilizadas contra a própria abordagem que as denunciava. A essa crítica Nietzsche responde: "Acontecendo de também isto ser apenas interpreta- ção e vocês se apressarão em objetar isso, não? - bem, tanto melhor!" (Nietzsche, 1992, pp. 28-29).

10 É preciso notar, neste ponto, que o alvo dessas objeções não está em criticar ou relativizar o trabalho de Walker. A questão colocada aqui diz respeito a até que ponto é possível levar as estratégias de desconstrução para além do que já foi feito no sentido de radicalizar ainda mais a possibilidade de crítica a um paradigma. Em outras palavras, já que conceitos como "soberania", "anarquia" e mesmo as especificidades das Relaçôes Internacionais já foram denunciados como produtos históricos de condições arbitrárias, como se pode proceder para que a desconstrução continue seu fluxo em busca de maior relatividade?

11 Isso não é algo que vá de encontro à prática da desconstrução. Como será discutido, até mesmo o processo de relativização necessita da manutenção de um ponto de referência para que um fenômeno possa ser desconstruído. No caso de Walker, o ponto balizador foi a história, que conserva em sua obra um sentido tradicional. A proposta, agora, é saber até que ponto esse processo de relativização por meio da denúncia de condições históricas pode continuar sendo eficaz no seu intento de crítica às condições analisadas. Para a possibilidade de desconstrução da noção tradicional de história, ver Fasolt (2004).

12 Em Assim falava Zaratustra, Nietzsche enumera as características do Übermensch apenas pela negação daquilo que o mesmo seria. Conceituar, nesse sentido, seria limitar e restringir a inovação aos padrōes já existentes (Nietzsche, 1985).

13 A partir dessa visão, Derrida irá trabalhar com a noção de rastro. Este seria a negação de uma origem primordial e a aceitação de que não existe um momento fundador. $\mathrm{O}$ rastro seria a continuidade daquilo que não é e, portanto, única herança possível do antigo ser. Isso, contudo, não significa que a noção de rastro tenha de ser considerada metafísica. Rastro seria justamente a presença possibilitada pela ausência. "A ausência de um outro aqui-agora, de um outro presente transcendental, de uma outra origem do mundo manifestando-se como tal, apresentando-se como ausência irredutível na presença do rastro, não é uma fórmula metafísica substituída por um conceito científico da escritura" (Derrida, 2004, p. 57).

14 Nessa citação, a autora se refere a Derrida. Ver Derrida (2004a).

15 Mais uma vez, a tradição nietzschiana aparece em Derrida. Assim como Nietzsche, Derrida acreditava serem as noções de verdade geradas por critérios 
morais. Deslocar, nesse sentido, seria o mesmo que tresvalorar (termo nietzschiano), ou seja, inverter as oposições morais. Ver Nietzsche (1992).

16 Repetição no sentido derridiano é a possibilidade de gerar sentidos pretensamente fixos a partir do constante movimento da existência. Isso significa a aceitação do ser e da mudança no sentido dado por Kierkegaard ao termo repetition. Para este autor, recollection seria a base de toda filosofia grega, seria o passo atrás, enquanto repetition seria a lógica do cristianismo, isto é, repetir a partir da inovação. Recollection e repetition seriam estratégias diferentes para lidar com a presença do constante fluxo. "Sem recollection ou repetition não há nada a não ser o fluxo, nada a não ser a desordem sem sentido. Recollection mantêm a desordem; repetition encontra uma forma de manter o sentido no meio disto. Recollection diz que tudo que é importante já aconteceu algum dia. Repetition diz que a atualidade precisa ser continuamente produzida, trazida à frente novamente, outra vez e outra vez. A identidade precisa ser estabelecida, produzida. A identidade, como Derrida diria, é um efeito da repetição" (Caputo, 1987 , p. 17 , tradução nossa).

17 Enquanto a teoria sistêmica de Saussure considera o contraponto como crucial na relação entre signos, a abordagem de Derrida chama a atenção para algo que vai além da simples contraposição. Para Saussure (2006), os signos somente são completos de sentidos quando colocados em posição de comparação com outros signos (em um processo que possibilita a verificação das semelhanças e diferenças entre eles). Para Derrida, não só a posição relativa dos signos é importante na produção de significação, como também a aceitação de que toda estrutura de sentido deve, necessariamente, conviver com elementos que se excluem em termos absolutos. Assim, o sentido não estaria na mera relação entre significante e significado ou no posicionamento horizontal dos signos, mas no ato de se estabelecer quais relações de sentido serão privilegiadas, em detrimento de várias outras relações possíveis. Utilizando o exemplo derridiano da palavra phármakon (termo que pode designar tanto "remédio" quanto "veneno"), teremos a produção de sentido somente no processo de decisão sobre qual dos dois se enfatizará (Derrida, 2005b). Em última instância, porém, a escolha de um dos sentidos apenas se estabelece enquanto o outro permanecer adormecido, ignorado pelo leitor. Assim, o que é contraponto necessário para gerar sentido, segundo Saussure, torna-se contradição imprescindível para esse mesmo processo, de acordo com Derrida.
18 Essa visão pressupõe que a manutenção das categorias tradicionais da relação entre tempo e espaço é imprescindível no trabalho proposto por Walker. Ir além, entretanto, significaria deslocar essa relação do centro estrutural e reacomodar as perspectivas críticas em busca de maior radicalidade.

19 Como bem observado por um parecerista anônimo, até certo ponto $\mathrm{R}$. Walker trabalha com a repetição enquanto crítica, utilizando autores clássicos da ciência política para desconstruir seus próprios legados. A diferença, contudo, estaria no fato de Walker trabalhar a repetição como recollection e não como repetition (ver nota 16).

\section{BIBLIOGRAFIA}

ARROJO, R. (org.). (1992), O signo desconstruido: implicações para a tradução, a leitura e o ensino. Campinas, Pontes.

ASHLEY, R. K. \& WALKER, R. B. J. (orgs.). (1990), "Speaking the language of exile: dissidence in international studies". International Studies Quarterly, 34 (3): 259-268.

BARNETT, C. (1999), "Desconstructing context: exposing Derrida". Transactions of the Institute of British Geographers, 24 (3): 277-293.

BEST, S. \& KELLNER, D. (1991), Postmodern theory: critical interrogations. Nova York, The Guilford Press.

CAPUTO, J. (1987), Radical hermeneutics: repetition, desconstruction and the hermeneutic project. Indianapolis, Indiana University Press.

DER DERIAN, J. \& SHAPIRO, M. J. (eds.). (1989), Internationallintertextual relations: postmodern readings of world politics. Lexington, Lexington Books.

DERRIDA, J. (2001), Posiçôes. Belo Horizonte, Autêntica.

(2004), Gramatologia. São Paulo, Perspectiva.

. (2005a), A escritura e a diferença. São

Paulo, Perspectiva. (2005b), A farmácia de Platão. São

Paulo, Iluminuras.

. (s. d.), A voz e o fenômeno. Lisboa, Ediçôes 70.

DERRIDA, J. \& ROUDINESCO, E. (2004), De que amanhã... Diálogo. Rio de Janeiro, Zahar. 
FASOLT, C. (2004), The limits of history. Chicago, Chicago University Press, 2004.

FIERKE, K. (2002), "Links across the abyss: language and logic in international relations". International Studies Quarterly, 46 (3): 331-354.

FOUCAULT, M. (2004a), A ordem do discurso. São Paulo, Loyola. . (2004b), Vigiar e punir. Petrópolis, Vozes.

GEORGE, J. (1994) Discourses of global politics: a critical (re)introduction to International Relations. Boulder, Lynne Rienner.

HANSEN, L. (2006), Security as practice: discourse analysis and the Bosnian war. Nova York, Routledge.

HUTTON, C. (1989), "The arbitrary nature of the sign". Semiótica, 75: 63-78.

KAFKA, F. (2002), Um artista da fome. São Paulo, Martin Claret.

KUBÁLKOVÁ, V.; ONUF, N. \& KOWERT, P. (eds.). (1998), International relations in a constructed world. Nova York, M. E. Sharpe.

MUSSALIM, F. \& BENTES, A. (orgs.). (2006), Introdução à linguistica 2: domínios e fronteiras. São Paulo, Cortez.

NIETZSCHE, F. (1992), Além do bem e do mal: prelúdio a uma filosofia do futuro. São Paulo, Companhia das Letras.

. (1985), Assim falava Zaratustra. São Paulo, Hemus.

(S. D.), Vontade de potência. Rio de Janeiro, Ediouro.

RAJAGOPALAN, Kanavillil. (1992), "A trama do signo: Derrida e a desconstrução de um projeto saussuriano", in R. Arrojo (org.), O signo desconstruido: implicaçôes para a tradução, a leitura e o ensino, Campinas, Pontes.

SAUSSURE, F. (2004), Escritos de linguística geral. São Paulo, Cultrix.

. (2006), Curso de linguística geral. São Paulo, Cultrix.

VEYNE, P. (1998), Como se escreve a história: Foucault revoluciona a história. Brasília, Editora da UnB.

WALKER, R. (1995), Insideloutside: international relations as political theory. Cambridge, Cambridge University Press. . (2003), "Polis, cosmopolis, politics". Al- ternatives, 28 (2): 267-286. . (2005), "The double outside of the modern international". Disponível em http:// www.uvic.ca/polisci/walker/publications.htm, consultado em 17/9/2007. . (2006), "Lines of insecurity: international, imperial, exceptional”. Security Dialogue, 37 (5): 65-82.

. (2010), After the globe, before the world. Abingdon, Routledge.

WENDT, A. (2003), Social theory of international politics. Cambridge, Cambridge University Press.

ZEHFUSS, M. (2002), Constructivism in international relations: the politics of reality. Cambridge, Cambridge University Press. 


\section{PÓS-ESTRUTURALISMO E A CRÍTICA COMO REPETIÇÃO}

\section{Cristiano Mendes}

Palavras-chave: Pós-estruturalismo; Crítica; Repetição; Derrida; Walker.

O presente artigo faz uma reflexão sobre as possibilidades de crítica a partir das abordagens pós-estruturalistas no âmbito das Relações Internacionais. Para isso, apresentamos um panorama da utilização do pós-estruturalismo neste campo de conhecimento destacando a obra de Robert Walker e sua crítica às correntes mainstream. Chamamos a atenção para o fato de que todo esforço de relativização empreendido pelo pós-estruturalismo necessita, de forma intrínseca, a aceitação de elementos já estabelecidos e imunes à relativização. Em seguida, apresentamos dois instrumentos utilizados por essa perspectiva teórica: a desconstrução e a tresvaloração. Elaboramos a partir daí uma reflexão sobre as possibilidades de posicionamento crítico. Ao final, concluímos que a repetição do paradigma a ser desconstruído deve ser considerada uma das formas possíveis de crítica em acordo com os pressupostos da abordagem teórica em questão.

\section{POST-STRUCTURALISM AND CRITICISM AS REPETITION}

\author{
Cristiano Mendes
}

Keywords: Post-Structuralism; Criticism; Repetition; Derrida; Walker.

This article examines the possibility of criticisms based on post-structuralist approaches in International Relations. In this sense, it offers a broad view about the use of post-structuralism in this knowledge field focusing on the approach of Robert Walker and his criticisms on the mainstream currents. In line with the author's relativistic view, it calls attention to the fact that any effort of relativization undertook by Post-Structuralism requires the intrinsic acceptance of previously established elements immune to this relativization. Following that, the article presents two instruments used in this theoretical perspective: deconstruction and transvaluation. From these two concepts, it elaborates on the possibilities of critical perspectives supported by Post-Structuralism. Finally, the article concludes that the repetition of the paradigm to be deconstructed ought to be considered one of the possible forms of criticism, according to the assumptions of the theoretical approach under consideration.

\section{LE POSTSTRUCTURALISME ET LA CRITIQUE EN TANT QUE RÉPÉTITION}

\section{Cristiano Mendes}

Mots clés: poststructuralisme; Critique; Répétition; Derrida; Walker.

Cet article propose une réflexion à propos des possibilités de critique à partir des abordages poststructuralistes dans le cadre des relations internationales. Nous présentons ainsi un panorama de l'utilisation du poststructuralisme dans ce domaine de savoir en mettant en évidence le travail de Robert Walker et sa critique aux courants mainstream. Nous attirons l'attention sur le fait que tous les efforts de relativisation entrepris par le poststructuralisme sous-entendent, de façon intrinsèque, l'acceptation des éléments établis et immunes à la relativisation. Nous présentons ensuite deux outils utilisés par cette perspective théorique: la déconstruction et la transvaluation. Nous avons, à partir de cela, préparé une réflexion sur les possibilités de positionnement critique. Finalement, nous avons conclu que la répétition du paradigme à être déconstruit doit être considéré comme l'une des formes possibles de critique conformément aux hypothèses de l'approche théorique en question. 